\title{
Mosaic Pattern of Sucrase Isomaltase Deficiency in Two Brothers
}

\author{
KONRAD REINSHAGEN, KLAUS M. KELLER, BIANCA HAASE, TOSSO LEEB, HASSAN Y. NAIM, AND KLAUS P. ZIMMER
}

\begin{abstract}
Department of Pediatric Surgery [K.R.], University of Heidelberg, D-68167 Mannheim, Germany; Department of Pediatrics [K.M.K.], DKD Wiesbaden, D-65011 Wiesbaden, Germany; Institute of Genetics [B.H., T.L.], Vetsuisse Faculty, University of Berne, CH-3001 Berne, Switzerland; Department of Physiological Chemistry [H.Y.N.], School of Veterinary Medicine, D-30559 Hannover, Germany; Department of Pediatrics [K.P.Z.], University Hospital Giessen, D-35392 Giessen, Germany
\end{abstract}

\begin{abstract}
The pathophysiology of mucosal changes observed in infants with chronic protracted diarrhea is poorly understood. We report on two brothers suffering from a special form of sucrase isomaltase (SI) deficiency. The children presented with weight loss and dyspepsia after sucrose exposition. We performed an $\mathrm{H}^{2}$ respiration test, which showed a pathologic result in the younger brother. Analysis of the brush border enzyme activities showed low expression of lactase and SI. Immunoelectron microscopy of duodenal biopsies showed an isolated SI deficiency in a mosaic pattern [e.g., $42 \%(14 \%)$ crypt enterocytes and 64\% (59\%) villus enterocytes with decreased amounts of SI on microvilli], whereas lactase and aminopeptidase $n(A p N)$ were present at the apical membrane of all cells in a normal range. The SI mosaic pattern of these patients shows that the enterocytes contain low amounts of SI on the apical membrane but express normal quantities of other disaccharidases. These findings suggest the existence of different clonal expressions or specific (posttranslational) mechanisms of postGolgi transportation for individual brush border enzymes. It remains unresolved whether the mosaic distribution is part of a normal maturation process or caused by a lack of an overall control mechanism in the expression of brush border hydrolases. (Pediatr Res 63: 79-83, 2008)
\end{abstract}

$\mathrm{C}$ ongenital sucrase isomaltase deficiency (CSID) is a rare autosomal recessive human intestinal disorder that is clinically characterized by fermentative diarrhea, meteorism, and occasionally failure to thrive. The usual presentation generally is at weaning from breast milk when infants are first exposed to the offending carbohydrates. Symptoms occur because of absence or significant reduction of digestive activities of sucrase and isomaltase, the components of sucrase isomaltase (SI), which is an integral membrane protein of the apical membrane of enterocytes. The mainstay of treatment is dietary restriction of sucrose-containing foods with additional substitution of the purified yeast enzyme, sacrosidase (1).

Investigations at the subcellular and molecular levels in intestinal biopsy specimens of patients with CSID have led to the description of several phenotypes that could be distinguished from each other based on altered transport competence, processing, and sorting of SI; reviewed by Naim and Zimmer (2). The present study describes two cases of atypical SI deficiency investigated in duodenal biopsy specimens taken from two brothers. Analysis of the tissue by immunoelectron

Received May 10, 2007; accepted August 14, 2007

Correspondence: Klaus P. Zimmer, M.D., Ph.D., Abt. Allgemeine Pädiatrie und Neonatologie, Feulgenstr. 12, 35385 Gießen, Germany; e-mail: Klaus-peter.zimmer@paediat.med. uni-giessen.de microscopy revealed an unusual mosaic pattern of SI. This pattern is not caused by altered histologic patterns of the tissue, which was fully normal. We addressed the question of whether the mosaic pattern of SI is limited to this protein or is a general phenomenon of the enterocytes in these patients and how these observations could be interpreted in terms of mechanisms that could be genetically based, for example, mutations of SI or elicited by altered biosynthesis and processing.

\section{PATIENTS AND METHODS}

The patients were two brothers of term, uncomplicated pregnancies and delivery without complications. The parents were both of European ethnic origin with no history of consanguinity. Both had been growing well and thriving until weaned from breast milk to formula at age $6-9$ mo when they began to have frequent stools and poor weight gain. Formula and diet changes were attempted without improvement. When they were seen by a pediatric gastroenterologist for the first time at the age of 9 mo and $2.5 \mathrm{y}$, physical examination showed alert, nondysmorphic infants. Severe reduction in muscle mass and subcutaneous fat was found in both patients. Growth and weight were below the third percentile. Frequent loss of watery stools was reported. $\mathrm{H}^{2}$ exhalation tests for disaccharidases were normal for rice starch and normal for SI in the older brother but pathologic in the younger brother (Fig. 1), excluding pandisaccharidase deficiency (3). The stools contained neither parasites nor pathogenic organisms. There were no signs for systemic inflammation in blood count; C-reactive protein was normal. When both brothers presented in our clinic for the first time, they were on a cow milk-free, lactose-free, and a gluten-free diet.

Because of the persistent acid diarrhea, a disaccharidase deficiency could not be excluded, and biopsy specimens were taken endoscopically. Mucosa examination showed normal aspects in the stomach and duodenum. Histologic examination of small bowel biopsies ( 3 biopsies of the older brother at different points of time and 1 biopsy of the younger brother) revealed a normal mucosa without intraepithelial lymphocytosis and a normal villus/crypt ratio of 4/1 without any evidence of infection or inflammation. Periodic acid-Schiff staining showed normal brush border localization and intensity. Analysis of enzyme activities was performed in homogenized mucosa, which showed unspecific low amounts of sucrase and lactase. Sucrase was $36.11 \mathrm{U} / \mathrm{g}$ protein in the younger and $17.87 \mathrm{U} / \mathrm{g}$ protein in the older brother; lactase was 25.12 in the younger and 12.89 in the older brother (Fig. 2).

Sucrose-free diet with enzyme replacement (Sucraid) was prescribed, resulting in a prompt cessation of diarrhea. The clinical status of both brothers improved in the following ways. The younger patient gained weight and height. The older brother remained under the third percentile despite the fact that he no longer suffered from diarrhea and flatulence. At the age of 7 and $9 \mathrm{y}$ respectively, control of an $\mathrm{H}^{2}$ exhalation test for SI and lactase revealed normal results in both patients (Fig. 1).

Because the diagnosis of primary SI deficiency could not be established by enzyme analysis, we performed immunocytochemistry for the brush border enzymes SI, lactase, and aminopeptidase $\mathrm{N}(\mathrm{ApN})$ to analyze and quantify the expression pattern of these proteins. Institutional review board approval was obtained from DKD Wiesbaden (Germany) as was informed consent from the parents before taking the biopsy specimen for diagnostic reasons.

Abbreviations: ApN, aminopeptidase N; CSID, congenital sucrase-isomaltase deficiency; LPH, lactase-phlorizin hydrolase; SI, sucrase isomaltase 


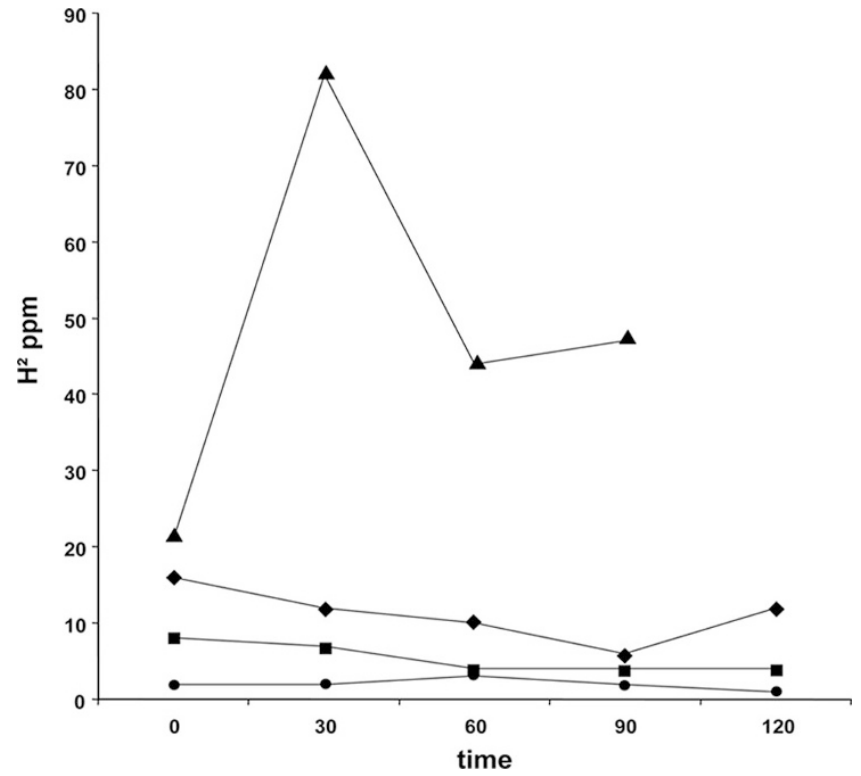

Figure 1. $\mathrm{H}^{2}$ exhalation test for sucrose. Sucrose was applied orally in a $10 \%$ solution. Overall amount sucrose was $1 \mathrm{~g} / \mathrm{kg}$ of the body weight. The older brother did not show increase in exhalation of $\mathrm{H}^{2}$ when diagnosis was made

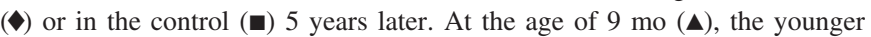
brother showed an increase of 62 parts per million of $\mathrm{H}^{2}$, which is highly pathologic. Five years later, the control $(\bullet)$ showed a normal curve after sucrose intake.

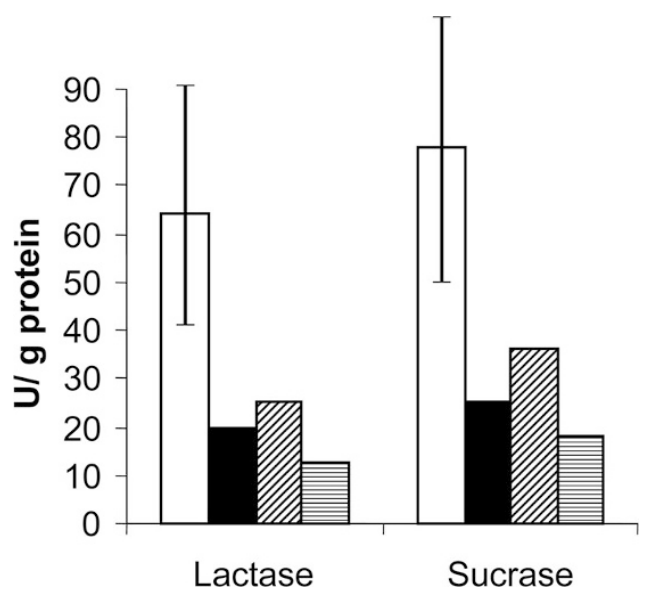

Figure 2. Enzyme activity for sucrase-isomaltase and lactase in the younger ( 四) and older (目) brothers compared with coeliac $(\square)$ and controls $(\square)$ patients. The activity is shown in IE/g protein of homogenized mucosa.

Immunoelectron microscopy. Biopsy samples were frozen in liquid nitrogen after fixation in 5\% paraformaldehyde in $50 \mathrm{mM}$ HEPES and cryoprotection by polyvinylpyrrolidone and sucrose. Sectioning and labeling of ultrathin frozen sections were carried out using a Leica EM Ultracut RFCS cryoultramicrotome (Leica, Bensheim, Germany) at -100 to $-110 \mathrm{C}^{\circ}$. Thawed sections were incubated for $45 \mathrm{~min}$ with a primary antibody and finally with goat anti-rabbit or anti-mouse immunogold (Dianova, Hamburg, Germany) consisting of $6 \mathrm{~nm}$ or $12 \mathrm{~nm}$ large gold particles at room temperature. The grids were contrasted with uranyl acetate, embedded in $2 \%$ methylcellulose containing $0.3 \%$ uranyl acetate, and examined with a Phillips 400 electron microscope (Phillips, Eindhoven, The Netherlands).

Antibodies. The polyclonal antibody antiSI was a generous gift from Dr. Alain Zweibaum (INSERM, Paris, France). The monoclonal antiSI antibodies were produced from the hybridoma cell lines HBB 2/614, HBB 2/219, and HBB 3/705. These antibodies recognize different epitopes in the SI protein and were therefore used together to visualize SI in the biopsy samples. The monoclonal anti-lactase phlorizin hydrolase (LPH) antibody was produced from the hybridoma cell line HBB 1/909 (4).

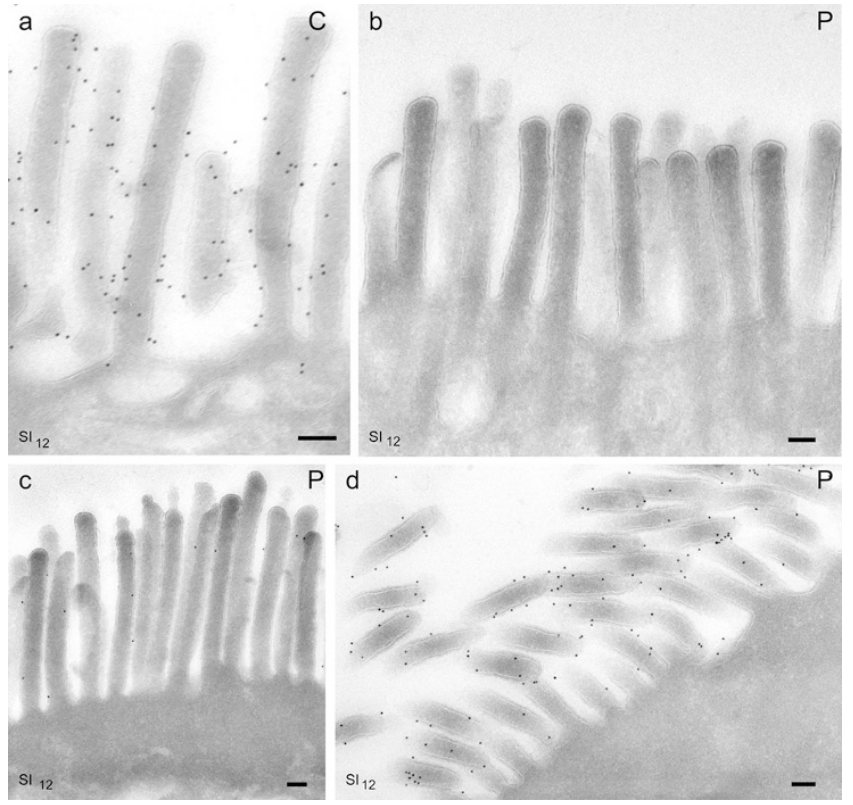

Figure 3. Thin frozen sections of control $(a)$ and patient $(b, c, d)$ small bowel biopsies labeled by antibodies against SI. Control showed a high density of labeling, whereas the patient (the younger brother) showed a mosaic pattern. Some cells showed very low density $(b)$ and intermediate density $(c)$ of SI, and others had a similar density of gold particles as the control cells $(d)$.

The antibodies HBB 2/614 and HBB 2/219 and both antiSI and HBB 1/909 and antiLPH immunoprecipitate SI and LPH under native conditions from normal biopsy extracts, their corresponding molecular forms, and their enzymatic activities. The antibody against ApN (CD13), subtype IgG1, was purchased from Dianova, product code CBL 169.

Quantitative evaluation of labeling densities. Quantification of the three enzymes, SI, lactase, and $\mathrm{ApN}$, at the apical membrane of enterocytes was assessed by counting the numbers of gold particles per membrane length of sectioned microvilli. Randomized electron microscopy pictures of each patient were taken from the apical part of enterocytes at a magnification of $\times 25,000$. The amount of gold particles per membrane was determined by point counting, as described elsewhere (5). Counting of gold particles was performed by two independent technical assistants on a blinded basis.

Genetic analyses. Genomic DNA was isolated from peripheral blood leukocytes of the two affected brothers and their parents. Individual SI exons were amplified using primers and polymerase chain reaction (PCR) conditions, as described in Sander et al. (6). The PCR products were treated with exonuclease I and shrimp alkaline phosphatase to remove residual primers and nucleotides. The PCR products were then directly sequenced using the BigDye v 3.1 kit and an ABI 3730 capillary sequencer (Applied Biosystems, Rotkreuz, Switzerland). Sequence data were analyzed with Sequencer 4.6 (GeneCodes, Ann Arbor, MI). Six single nucleotide s (SNPs) corresponding to the dbSNP accessions 7629658, 34576093, 9865476, 9290256, a novel A/G SNP in intron 41 designated IVS41 + 9A > G, and 3762796 were genotyped in all family members. Haplotypes from the SNP genotypes were calculated with Merlin (7).

\section{RESULTS}

Subcellular localization of SI in patient biopsies. Subcellular localization of the SI molecule in the patients' tissue was assessed by antibody-specific immunogold staining. With immunogold staining, SI molecules were detected regardless of whether they were in an active, inactive, or mannose-rich form.

The labeling density strongly differed between enterocytes in contrast with control biopsies (Fig. 3a). Immunogold particles were detected at the apical membrane to different extents, varying from total absence to dense labeling (Fig. $3 b, c$, and $d$ ). The number of enterocytes with 
complete lack of SI was approximately $5 \%$. The control biopsies showed strong SI labeling at the apical membrane of all enterocytes (Fig. 3a).

Colocalization of SI with lactase or ApN. The enterocytes of the patients with low labeling densities for SI at the apical membrane showed mostly a strong labeling for lactase (Fig. 4a) and ApN (Fig. 4b) at the brush border membrane. We did not find any correlation of SI expression level with lactase and ApN, although the labeling densities for the latter proteins varied between enterocytes to some

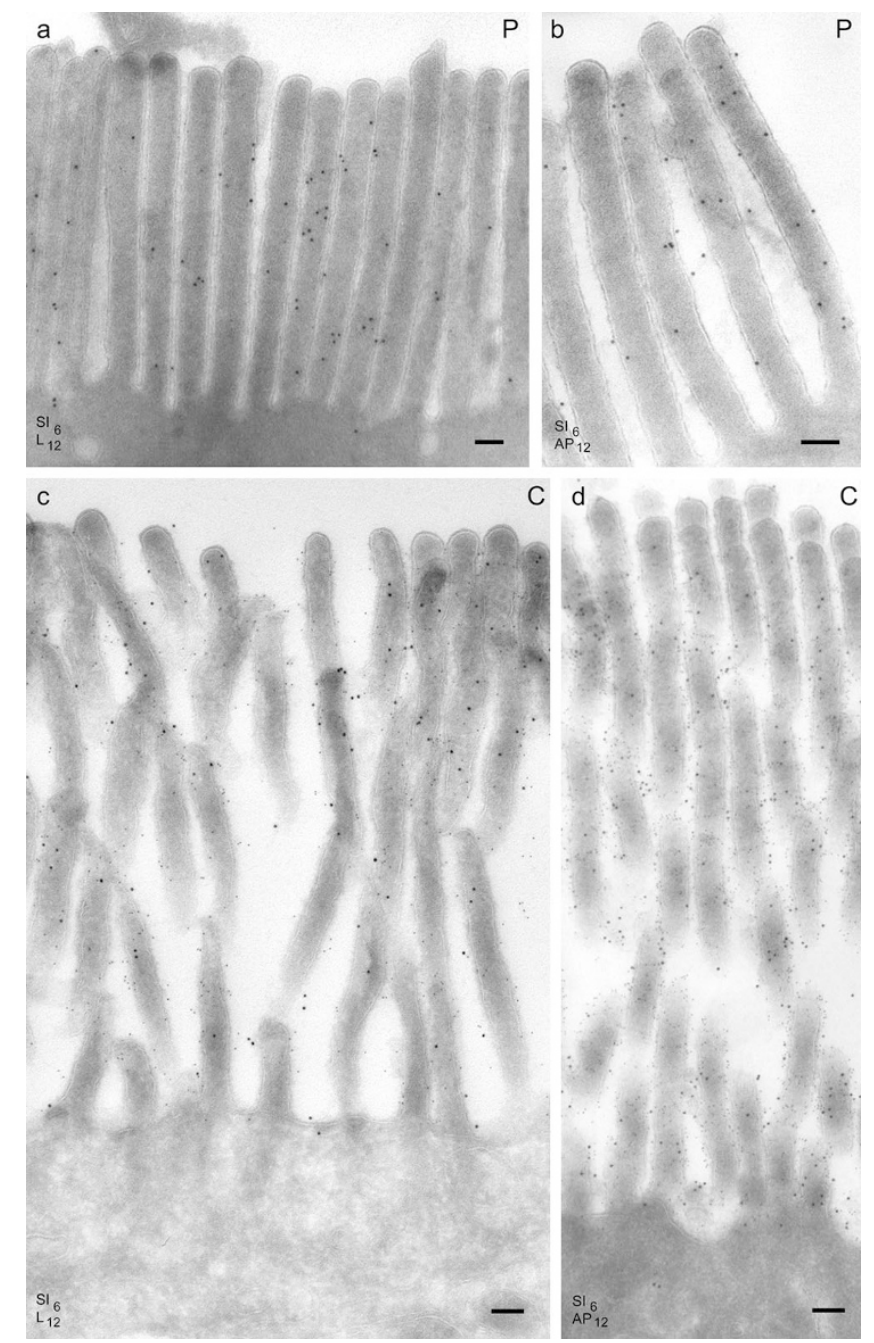

Figure 4. Colabeling of thin frozen sections of small bowel biopsies with antibrush border proteins. Sections of small bowel biopsies were simultaneously labeled by antibodies against SI and lactase $(a, c)$ or SI and $\mathrm{ApN}(b$, $d)$. The patients biopsies $(a, b)$ show similar labeling densities for the lactase and ApN as the control biopsies $(c, d)$. There is a lack of small immunogold particles in the patient biopsies $(a, b)$, indicating a lower concentration of SI compared with the controls $(c, d)$. extent. The labeling densities of lactase and ApN appeared lower than that of SI because large gold particles were used in the immunolocalization of lactase and $\mathrm{ApN}$ and small gold particles for SI. In control biopsies, we could detect enterocytes, which showed similar strong labeling densities for SI, lactase, and ApN, although a strong correlation between SI labeling on one side and lactase or ApN labeling on the other side was also not found.

Quantitative analysis of brush border enzymes at the apical membrane. Quantitative analysis was performed on frozen sections of control and patient biopsies with a doublelabeling technique. We compared the labeling of SI with that of lactase and, in a second analysis, SI with ApN. Variable levels of SI were observed in both patients. Lactase and ApN showed no significant differences between the patients and controls. Finally, ApN showed a substantial reduction in its expression levels in the older patient (Table 1).

To compare the expression of different brush border enzymes at the cellular level, we performed colocalizations of SI and lactase or ApN. These experiments revealed that the level of lactase within individual enterocytes of patients as well as control biopsies does not correlate with that of SI within the same enterocytes (Fig. 5a). Likewise, there exists no correlation between the levels of $\mathrm{ApN}$ and SI within the same cells (Fig. 5b).

In these analyses, we performed a cutoff at a very low concentration of SI in the control biopsies (approximately 4.8 $\mathrm{gp} / \mu \mathrm{m}^{2}$ ). The cells with a SI concentration under the cutoff were defined as SI deficient. In both patients, we found a mosaic pattern of SI expression; the older brother showed $42 \%$ crypt enterocytes and $64 \%$ villus enterocytes, and the younger brother showed 14\% crypt enterocytes and 59\% villus enterocytes with a low SI concentration at the apical membrane.

Genotyping. Twenty-nine of the 48 exons of the SI gene were sequenced in the patients and their parents. No known pathologic mutation was found in the sequenced regions. Furthermore, no other mutation that appeared likely to be causative for a deficiency in SI was found. However, several polymorphisms in introns of the SI gene were segregated in the investigated family (Fig. 6). The segregation pattern of these polymorphisms indicated that the two affected brothers did not receive the same SI haplotype from their mother; however, the two brothers inherited two different haplotypes from their father. In assuming a recessive inheritance of CSID, this finding excludes mutations within the $S I$ gene as the cause for the observed phenotype of the two brothers.

Table 1. Amount of different brush border enzymes at the apical membrane in gold particles per membrane length

\begin{tabular}{|c|c|c|c|c|c|c|}
\hline \multirow{2}{*}{$\begin{array}{c}\text { Brush border } \\
\text { hydrolases/gp/ } \mu \mathrm{m}\end{array}$} & \multicolumn{2}{|c|}{ Older brother } & \multicolumn{2}{|c|}{ Younger brother } & \multicolumn{2}{|c|}{ Control } \\
\hline & Crypts & Villus & Crypts & Villus & Crypts & Villus \\
\hline SI & $4.1 \pm 2.2$ & $3.2 \pm 2.1$ & $8 \pm 4.3$ & $3.7 \pm 3.2$ & $9.1 \pm 4.5$ & $8.4 \pm 3.5$ \\
\hline Lactase & $0.9 \pm 0.4$ & $1.1 \pm 0.9$ & $0.4 \pm 0.7$ & $1.1 \pm 0.5$ & $0.6 \pm 0.8$ & $1.4 \pm 1$ \\
\hline Aminopeptidase & $0.3 \pm 0.4$ & $1.0 \pm 0.9$ & $1.7 \pm 0.7$ & $1.7 \pm 0.6$ & $1.8 \pm 1.1$ & $1.6 \pm 0.9$ \\
\hline
\end{tabular}


a)

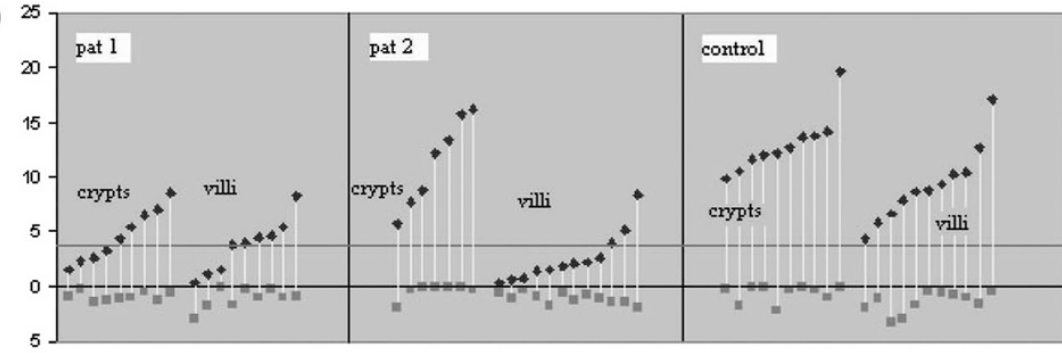

b)

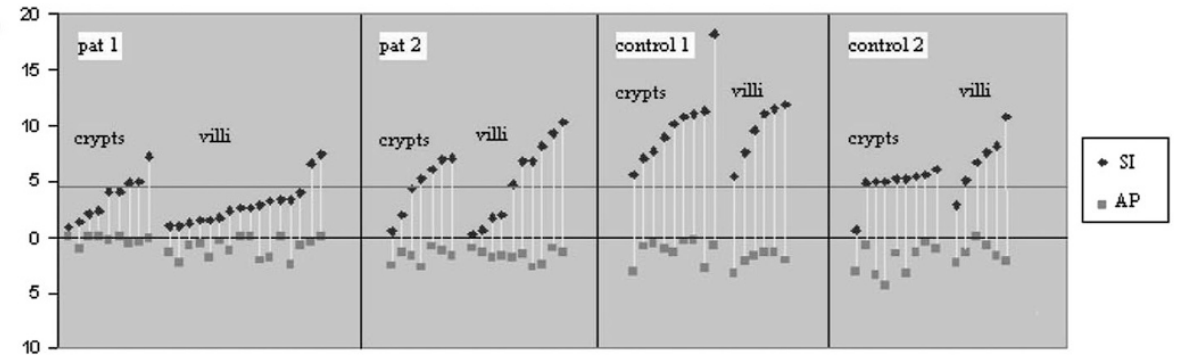

Figure 5. Comparison between the expression levels of different hydrolases within one cell. SI reveals a mosaic pattern in the enterocytes as shown by variations in the labeling intensity. (a) Amount of SI and lactase within cells of both patients and a control. (b) SI and $\mathrm{ApN}$ of both patients and two controls. There is no correlation between the mosaic pattern of labeling of SI on one hand and the labeling of lactase or $\mathrm{ApN}$ in the individual cells on the other.

\section{DISCUSSION}

CSID is a rare autosomal recessive disorder characterized by a complete absence of the sucrase activity and an isomaltase activity that varies form absent to normal. In some cases, maltase glucoamylase activity was also decreased. Several phenotypes generated by different point mutations and even in the coding region of the SI protein have been described $(2,6,8,9)$.

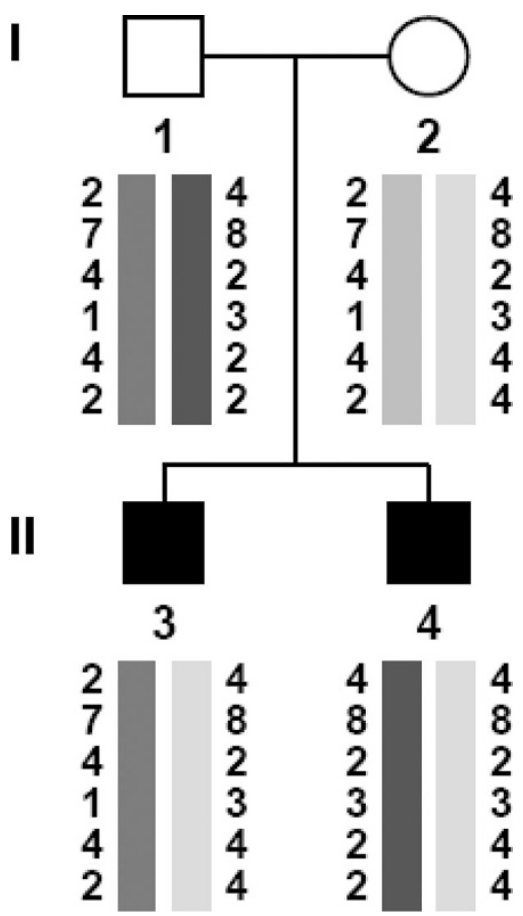

Figure 6. Genotyping data of SI polymorphisms in the investigated family. Normal father $(\square)$ and mother $(\bigcirc)$. Two affected sons of this family ( $\square$ ). Marker genotypes at six informative polymorphisms within the SI gene indicated. The polymorphisms are evenly distributed in the SI gene between exon 1 and intron 45 . The segregation of the $S I$ haplotypes shows that the two brothers inherited different chromosomes from their father. Thus, it is highly unlikely that recessive mutations in the SI gene are responsible for the observed phenotype.
In the present study, two cases of a nonCSID SI deficiency are described in which a mosaic pattern of expression of SI is revealed within the intestinal epithelium of the SI-deficient patients. Therefore, these phenotypes differ substantially from the current "point-mutation" concept of CSID and suggest an entirely novel mechanism in the onset of this disease.

When the patients presented for the first time with failure to thrive, diarrhea, and flatulence, the major problem was to set diagnosis of SI deficiency. Only the younger brother described herein showed pathologic $\mathrm{H}^{2}$ exhalation test for sucrose (performed at the age of $9 \mathrm{mo}$ ), whereas an $\mathrm{H}^{2}$ test for lactase was normal. Enzyme activity examination of the homogenized mucosa of both patients showed only unspecific, low concentrations for both lactase and sucrase. Diagnosis of congenital SI deficiency could not be established, but clinical response to Sucraid supplementation suggested reduced sucrase activity at the brush border membrane. Therefore, we performed immunocytochemistry for the brush border enzyme SI in comparison with lactase and ApN.

With electron microscopy, we found normal morphology of the epithelial cells, but, in some cells, expression of SI was much lower or even absent than in other cells. Quantification showed a mosaic expression of the brush border enzyme SI, whereas lactase and $\mathrm{ApN}$ showed a more regular distribution at the apical membrane of the same enterocytes. Because SI is synthesized by crypt and villus cells (10), we found the mosaic expression of SI in all enterocytes on the crypt-villus axis.

It has been already shown by Naim et al. (11) that, in CSID, other brush border enzymes are expressed at normal levels and patterns. In biosynthetic labeling studies of the brush border enzymes in all CSID phenotypes described so far, it was shown that the absence of active SI was caused by altered folding and trafficking of SI and is not the consequence of a more general cellular defect, for example, in the glycosylation or trafficking machineries. In our patients, we could now visualize an isolated mosaic expression of SI with a normal expression of lactase or ApN within the enterocytes lacking SI. Such a phenomenon has been described in vivo for lactase 
(12) and in vitro for SI in Caco-2 clones and HT-29-18-C1 subclones that have been cultured under high glucose consumption $(13,14)$. Moreover, double immunostaining of different brush border enzymes in Caco-2 cells revealed that there is no correlation in the expression levels of lactase or $\mathrm{ApN}$ and SI. Altogether, these studies and our observations are compatible with a lack of an overall control mechanism for gene expression of the brush border enzymes (15). In vivo experiments have demonstrated that the regulation of brush border hydrolases is achieved by the transcriptional repressor PDX-1 (16) at the posttranscriptional level (17). Nevertheless, recent observations suggest a possible role for trafficking pathways in the regulation and control of the expression of brush border membrane proteins at the apical surface. In fact, the brush border enzymes SI and lactase are transported in different vesicle populations to the cell surface by using independent post trans-Golgi network routes (18). SI is transported in vesicles along actin tracks, guided by myosin $1 \mathrm{~A}$, whereas lactase is transported in an actin-independent pathway to the apical membrane (19). Hypothetically, there is a defect in one of these routes; for example, down-regulation of the actin-dependent transport mechanism could result in a reduced concentration of SI at the apical membrane with a normal amount of lactase within the brush border. This hypothesis is supported by the fact that we found a low but similar enzyme activity of different brush border enzymes in the homogenized mucosa.

Although genotyping of SI did not indicate a genetic background of the present mosaic, it remains unresolved in our patients at which level the expression of the examined brush border hydrolases is regulated. Because of the mosaic form of SI expression at the cellular level and the lack of correlation of SI with lactase and ApN at the apical membrane, it remains unclear whether there is an overall control mechanism for gene expression in the enterocytes. It would be of interest to examine the distribution of mRNA by in situ hybridization to determine whether mosaicism at the SI mRNA level is present in our patients.

Regardless of the level at which the regulation of the brush border enzymes occurs, we found the SI deficiency, which was possibly of secondary nature, to be a temporary problem of our patients. Improvement of clinical conditions was associated with normal $\mathrm{H}^{2}$ test in the follow-up after $5 \mathrm{y}$. Investigations in the growing rat showed a temporary mosaic expression of SI during the time of weaning from milk. Here, SI was first detected in the newborn rats at day 16 with patchy expression, and later, on day 21, SI was abundant in all enterocytes (20). It is well known that SI activity increases when lactase decreases and remains at a high level throughout further development. The exact distribution and pattern of expression of the brush border enzymes around the time of weaning has not been studied at the cellular level. It could be suggested that the mosaic expression of SI in our patients is part of normal maturation, with the exception that, in our patients, there is a delay in a maturation or adaptation process. This would be supported by the fact that, with aging of our patients, there are no longer clinical findings, and follow-up examination of $\mathrm{H}^{2}$ exhalation test showed normal results for both brothers. This is in line with the fact that tolerance to starch improves during the first years of life in SI-deficient patients.

Mosaic expression for SI demonstrated in two brothers and combined with a normal expression of other brush border enzymes (lactase, ApN) within the same individual enterocytes has not been described before. Our results point to an adaptation process of the mucosa (potentially secondary to an injury) and support in vitro data that brush border hydrolases are expressed without an overall control mechanism.

Acknowledgments. The authors thank Cordula Westermann for excellent technical assistance, Dr. A. Zweibaum for the polyclonal antibody against sucrase-isomaltase, Dr. HansPeter Hauri, Biozentrum Basel, and Erwin Sterchi, University of Berne, for the monoclonal antiSI and antilactase antibodies.

\section{REFERENCES}

1. Treem WR, McAdams L, Stanford L, Kastoff G, Justinich C, Hyams J 1999 Sacrosidase therapy for congenital sucrase-isomaltase deficiency. J Pediatr Gastroenterol Nutr 28:137-142

2. Naim H, Zimmer KP. 2004 Genetically determined disacharidase deficiency. In: Walker, Goulet, Kleinman, Sherman, Shneider, Sanderson (eds) Pediatric Gastrointestinal Disease. Mosby Co, Orlando, pp 880-887

3. Mainguet P, Vanderhoeden R, Loeb H 1973 Congenital maltase-sucrase and maltase-isomaltase deficiency in an adult. Digestion 8:353-359

4. Hauri HP, Sterchi EE, Bienz D, Fransen JA, Marxer A 1985 Expression and intracellular transport of microvillus hydrolases in human intestinal epithelial cells. J Cell Biol 101:838-851

5. Griffiths G 1993 Fine Structure Immunocytochemistry. Springer, Heidelberg

6. Sander P, Alfalah M, Keiser M, Korponay-Szabo I, Kovacs JB, Leeb T, Naim HY 2006 Novel mutations in the human sucrase-isomaltase gene (SI) that cause congenital carbohydrate malabsorption. Hum Mutat 27:119

7. Abecasis GR, Cherny SS, Cookson WO, Cardon LR 2002 Merlin-rapid analysis of dense genetic maps using sparse gene flow trees. Nat Genet 30:97-101

8. Jacob R, Zimmer KP, Schmitz J, Naim HY 2000 Congenital sucrase isomaltase deficiency arising from cleavage and secretion of a mutant form of the enzyme. J Clin Invest 106:281-287

9. Fransen JA, Hauri HP, Ginsel LA, Naim HY 1991 Naturally occurring mutations in intestinal sucrase-isomaltase provide evidence fort he existence of an intracellular sorting signal in the isomaltase subunit. J Cell Biol 115:45-57

10. Beaulieu JF, Nichols B, Quaroni A 1989 Posttranslational regulation of sucraseisomaltase expression in intestinal crypt and villus cells. J Biol Chem 264:2000020011

11. Naim HY, Roth J, Sterchi EE, Lentze M, Milla P, Schmitz J, Hauri HP 1988 Sucrase-isomaltase deficiency in humans. Different mutations disrupt intracellular transport, processing, and dysfunction of an intestinal brush border enzyme. J Clin Invest 82:667-679

12. Maiuri L, Raia V, Potter J, Swallow D, Wan Ho M, Fiocca R, Finzi G, Cornaggia M, Capella C, Quaroni A, Auricchio S 1991 Mosaic pattern of lactase expression by villous enterocytes in human adult-type hypolactasia. Gastroenterology 100:359369

13. Chantret I, Rodolosse A, Barbat A, Dussaulx E, Brot-Laroche E, Zweibaum A, Rousset M 1994 Differential expression of sucrase-isomaltase in clones isolated from early and late passages of the cell line Caco-2: evidence for glucose-dependent negative regulation. J Cell Sci 107:213-225

14. Huet C, Sahuquillo-Merino C, Coudirer E, Louvard D 1987 Absorptive and mucus-secreting subclones isolated from multipotent intestinal cell line (HT-29) provide new models for cell polarityand terminal differentiation. J Cell Biol 105:345-357

15. Vachon PH, Perrault N, Magny P, Beaulieu JF 1996 Uncoordinated, transient mosaic patterns of intestinal hydrolase expression in differentiating human enterocytes. J Cell Physiol 166:198-207

16. West AR, Oates PS 2005 Decreased sucrase and lactase activity in iron deficiency is accompanied by reduced gene expression and upregulation of the transcriptional repressor PDX-1. Am J Physiol Gastrointest Liver Physiol 289:G1108-G1114

17. Marion J, Petersen YM, Romé V, Thomas F, Sangild PT, Dividich J, Huerou-Luron I 2005 Early weaning stimulates intestinal brush border enzyme activities in piglets, mainly at the posttranscriptional level. J Pediatr Gastroenterol Nutr 41:401-410

18. Jacob R, Heine M, Alfalah M, Naim HY 2003 Distinct cytoskeletal tracks direct individual vesicle populations to the apical membrane of epithelial cells. Curr Biol 13:607-612

19. Jacob R, Naim HY 2001 Apical membrane proteins are transported in distinct vesicular carriers. Curr Biol 11:1444-1450

20. Rings EH, Krasinski SD, van Beers, EH Moorman AF, Dekker J, Montgomery RK, Grand RJ, Buller HA 1994 Restriction of lactase gene expression along the proximal-to-distal axis of rat small intestine occurs during postnatal development. Gastroenterology 106:1223-1232 